\title{
Conselhos Estaduais de Educação nos Novos Planos Estaduais de Educação
}

\author{
Rosimar de Fátima Oliveira' \\ Donaldo Bello de Souza" \\ Adriane Peixoto Câmara'
}

'Universidade Federal de Minas Gerais (UFMG), Belo Horizonte/MG - Brasil "Universidade do Estado do Rio de Janeiro (UERJ), Rio de Janeiro/RJ - Brasil

RESUMO - Conselhos Estaduais de Educação nos Novos Planos Estaduais de Educação. Este estudo, de caráter exploratório e descritivo, pautado na análise de conteúdo, visa ao exame do papel que os Conselhos Estaduais de Educação (CEEs) eventualmente assumem nos Planos Estaduais de Educação (PEEs) alinhados ao PNE 2014-2024, seja em relação à gestão estadual dos seus sistemas de ensino, seja, de modo mais específico, em termos da elaboração e consecução do próprio plano. Como conclusão mais geral, verifica que os CEEs apresentam, desde a sua criação, trajetória histórica declinante, cujos reflexos se fazem observar nesses planos: na ausência de protagonismo relativo à sua elaboração, no esvaziamento das competências como órgãos dos Sistemas Estaduais de Ensino e, ainda, na fragilidade referente ao aporte do sistema para sua infraestrutura.

Palavras-chave: Planos Estaduais de Educação. Conselhos Estaduais de Educação. Plano Nacional de Educação. Gestão Democrática da Educação.

ABSTRACT - State Education Councils in New State Education Plans. This exploratory and descriptive study, based in the analysis of content, aims to examine the role that the State Education Councils (CEEs) eventually occupies in the State Education Plans (PEEs) aligned to the PNE 2014-2024, whether in relation to the state management of their education systems, either, more specifically, in terms of the development and implementation of the plan itself. As a more general conclusion, it was observed that the CEEs feature, since their creation, a declining historical trajectory, whose effects are observed in these plans: in the absence of leadership for their preparation, in draining of the competences as bodies of the State Education Systems, and in terms of the fragility of the system in supplying its structure. Keywords: State Education Plans. State Education Councils. National Education Plan. Democratic Management of Education.

Educação \& Realidade, Porto Alegre, v. 43, n. 2, p. 669-690, abr./jun. 2018. 669 http://dx.doi.org/10.1590/2175-623666162 
Conselhos Estaduais de Educação nos Novos Planos Estaduais de Educação

\section{Introdução}

De modo geral, os Sistemas Estaduais de Ensino no Brasil possuem, a par de outras instâncias, dois órgãos superiores de administração da educação estadual que, em tese, devem atuar de forma articulada: a Secretaria de Estado de Educação (SEDUC) e o Conselho Estadual de Educação (CEE). O primeiro órgão, predominantemente executivo, exerce funções de coordenação, supervisão, articulação e implementação das políticas e ações educacionais. Já o segundo, órgão preponderantemente normativo, também com competências de assessoramento, atua na fiscalização e controle e, ainda na proposição de políticas educacionais locais (Conselho..., 2010; Brasil, 1996a).

No caso dos CEEs, em que pese o fato de o valor de sua função nos Sistemas Estaduais de Ensino se fazer notar na quase totalidade das Constituições Estaduais (CEs) do País, sobretudo em termos da centralidade assumida por sua competência normativa (Cury, 2001), o mesmo não pode ser dito em relação ao planejamento estadual decenal da educação. Estudos recentes sobre os Planos Estaduais de Educação (PEEs) alinhados ao Plano Nacional de Educação (PNE) 2001-2010 (Brasil, 2001) têm revelado, por exemplo, a não consideração desses Conselhos "[...] como lócus privilegiado para a coordenação e/ou construção do plano" (Souza; Menezes, 2015, p. 926), além da minoração da sua importância como órgão colegiado constitutivo do Sistema Estadual de Ensino, pouco contribuindo, com isto, "[...] para a qualidade técnica e social do acompanhamento e avaliação da implantação desses PEEs” (Souza; Menezes, 2016, p. 313).

De modo subjacente, tal ausência se faz notar na esfera do próprio PNE 2001-2010, cuja única menção direta ao CEE ocorre na discussão das diretrizes relativas ao Ensino Fundamental, quando a sua função normativa é aludida pela recomendação de que a adoção dos novos paradigmas curriculares, como a interdisciplinaridade e a transversalidade, devem observar, além das diretrizes emanadas pelo Conselho Nacional de Educação (CNE), a "[...] dos conselhos de educação dos Estados e Municípios” (Brasil, 2001, p. 14). Indiretamente, sem nomear o órgão responsável pela coordenação do processo de implantação e desenvolvimento dos planos nacional e subnacionais, o PNE 2001-2010 destaca apenas que demandam por uma “[...] coordenação em âmbito nacional, de uma coordenação em cada Estado e no Distrito Federal e de uma coordenação na área de cada Município, exercidas pelos respectivos órgãos responsáveis pela Educação” (Brasil, 2001, p. 57).

Já no âmbito do novo PNE, aprovado pela Lei n. 13.005, de 25 de junho de 2014 (Brasil, 2014), para o período 2014-2024 -, nenhuma referência, direta ou indireta, é feita ao CEE. Ao contrário, quando determina que "A União, os Estados, o Distrito Federal e os Municípios atuarão em regime de colaboração, visando ao alcance das metas e à implementação das estratégias objeto deste Plano” (Brasil, 2014, art. 7º, caput), condiciona "[...] a instituição de instâncias permanentes de negociação, cooperação e pactuação em cada Estado” (Brasil, 2014, art. 7º, \$6º). Sem

670 Educação \& Realidade, Porto Alegre, v. 43, n. 2, p. 669-690, abr./jun. 2018. 
nomear tais instâncias, tudo leva a crer que não se trata dos CEEs, órgãos há muito instituídos, pois, conforme salienta Abicalil (2014), ainda caberia definir a composição representativa das instâncias propostas, suas finalidades, procedimentos e uso de recursos.

No vácuo da competência dos CEEs na esfera do PNE 2014-2024 (Brasil, 2014), caberia inicialmente indagar sobre a sua presença nos PEEs elaborados ou adequados em consonância a este novo PNE, sobretudo em relação ao papel que eventualmente assumem, seja no âmbito da gestão estadual dos seus sistemas de ensino, seja, de modo mais específico, em relação à elaboração e consecução do próprio plano estadual.

De modo a tentar dar resposta às questões acima, o presente estudo, de caráter exploratório e descritivo (Ketele; Roegiers, 1993), se pauta na análise de conteúdo (Bardin, 2004) de documentos legislativos relativos aos PEEs efetivamente transformados em norma jurídica, ou seja, aprovados pelo legislativo, sancionados pelo executivo e, ainda, publicados em órgão oficial do estado correspondente, alinhados ao PNE 2014-2024. Para tanto, recorreu à realização de levantamento documental exaustivo em torno desses planos e de suas respectivas leis de criação, num primeiro momento com base na página da Internet relativa ao Ministério da Educação (MEC), intitulada PNE em Movimento: situação dos planos de educação $0^{1}$ para, em seguida, ampliar a busca por outras versões desses documentos, agora lançando mão de bases pertencentes às Assembleias Legislativas dos 26 estados da Federação e aos respectivos Diários Oficiais dos Estados, assim como de páginas correspondentes às SEDUCs dos sistemas de ensino em questão.

Além desta seção introdutória, o artigo está composto por outras quatro partes. Na próxima, estabelece um breve histórico sobre o processo de institucionalização dos CEEs no Brasil e, na sequência, traça um panorama acerca da situação atual dos PEEs consoantes ao novo PNE. Sob perspectiva quantitativa, na terceira seção, examina o papel atribuído a esses Conselhos no âmbito dos PEEs em questão para, em seguida, formular as conclusões finais.

\section{A Institucionalização dos Conselhos Estaduais de Educação}

A Constituição Federal de 1934 (Brasil, 1934) foi o primeiro instrumento jurídico a dispor sobre os CEEs. No seu art. 152, ao atribuir competência ao então CNE para elaborar o PNE e sugerir medidas para solucionar os problemas educativos, bem como a distribuição adequada dos fundos especiais², especifica no parágrafo único que: “[...] os Estados e o Distrito Federal, na forma das leis respectivas e para o exercício da sua competência na matéria, estabelecerão Conselhos de Educação com funções similares às do Conselho Nacional de Educação" (Brasil, 1934, art. 152) ${ }^{3}$. Porém, conforme sinaliza Cury (2001), o status constitucional do CEE resumiu-se a esta norma, uma vez que, a partir de então, em âmbito federal, a regulamentação sobre sua criação e funcionamento se deu por meio, exclusivamente, de legislação infraconstitucional, seja 
Conselhos Estaduais de Educação nos Novos Planos Estaduais de Educação

de forma explícita - como no caso da Lei n. 4.024, de 20 de dezembro de 1961 (Brasil, 1961) e da Lei n. 5.692, de 11 de agosto de 1971 (Brasil, 1971) - ou implícita - como no caso da Lei n. 9.394, de 20 de dezembro de 1996 (Brasil, 1996a).

Estabelece a Lei n. 4.024/1961 (Brasil, 1961, art. 10) que os CEEs:

[...] organizados pelas leis estaduais, que se constituírem com membros nomeados pela autoridade competente, incluindo representantes dos diversos graus de ensino e do magistério oficial e particular, de notório saber e experiência, em matéria de educação, exercerão as atribuições que esta lei lhes consigna.

Desse modo, os CEEs são criados e suas funções atribuídas no mesmo compasso em que se dava a organização dos sistemas federal e estadual de ensino, de modo a expressar uma dinâmica federativa em que os estados exerciam o controle administrativo e político sobre a oferta educacional no âmbito dos respectivos territórios. Naquele momento, os Sistemas Estaduais de Ensino integravam as escolas públicas e particulares do então Ensino Primário e Médio (incluindo as escolas municipais) ${ }^{4}$, bem como as instituições estaduais e municipais de Ensino Superior. Integrantes do Sistema Estadual de Ensino, os CEEs exerciam suas atribuições normativas, deliberativas e opinativas no âmbito desses respectivos sistemas (Boaventura, 1992). Portanto, a premissa de que só haveria sistema de ensino em conformidade com a atuação do respectivo órgão colegiado é um legado da Lei n. 4.024/1961.

Para os CEEs, a Lei n. 4.024/1961 é um marco normativo fundante, pois dispõe sobre a sua organização, instituindo-os como órgãos que, no âmbito dos estados, exercerão, assim como dispunha a Constituição Federal de 1934, funções correlatas àquelas atribuídas ao Conselho Federal de Educação (CFE). No âmbito da referida legislação, os CEEs manteriam com o CFE uma relação de articulação e não de subordinação, como interpretou o conselheiro Newton Sucupira, em documento publicado por este órgão (Brasil, 1963). Segundo ele, a Lei n. 4.024/1961, quis assegurar

[...] maior entrosamento entre os Conselhos determinando, expressamente, que o Conselho Federal promovesse aquele intercâmbio. Entrosamento que não se faria apenas em função dos dispositivos que garantem a unidade básica do sistema, mas nasceria de um contato vivo e fecundo entre essas instituições. [...] Os Conselhos Estaduais [...] são órgãos autônomos que não se acham subordinados ao Conselho Federal. [...] A lei, não se contentando com a ação isolada dos órgãos colegiados encarregados de sua execução, estabeleceu, expressamente, um dispositivo destinado a promover uma interação real entre eles, incumbindo ao Conselho Federal a tarefa de manter intercâmbio entre os Conselhos (Brasil, 1963, p. 3, grifo no original).

Além da preocupação com um intercâmbio produtivo entre o CFE e os CEEs, o conselheiro Newton Sucupira tipifica, a partir da Lei 
n. 4.024/1961, um modelo de conselho de educação que, no âmbito dos estados, apresentar-se-iam como órgãos autônomos e indispensáveis aos sistemas de ensino. Mais do que isso: a partir das suas considerações, fica mais evidente, quando da defesa de encontros frequentes entre o CFE e os CEEs, a perspectiva de um alinhamento estratégico entre ambos a partir de três pontos: “1) o princípio da descentralização articulada; 2) o sentido geral de planejamento de que se reveste a lei; 3) o objetivo de concretizar uma autêntica educação nacional" (Brasil, 1963, p. 6). Desta maneira, mais do que ratificar um modelo de conselho de educação cujo papel era de relevância no âmbito dos Sistemas Estaduais de Ensino, o conselheiro expressa sua preocupação quanto à articulação em torno de um ideal comum para a Educação Nacional. Tal articulação aconteceria a partir do poder emanado pelos CEEs em articulação com o CFE. Esta perspectiva, que se encontra também expressa no documento oficial do CFE em tela (Brasil, 1963), assim, destaca esses Conselhos como órgãos de Estado, atribuindo-lhes competências tanto no planejamento educacional local, como na interação deste com as políticas educacionais nacionais e regionais. É, portanto, uma concepção poderosa acerca desses órgãos, pois atribui aos mesmos um papel que vai além da normatização e do assessoramento nos seus respectivos sistemas de ensino.

A reformulação da Lei n. 4.024/1961, na década seguinte, por meio da Lei n. 5.692/1971, manteve o CEE como órgão normativo, atribuindo-lhe funções específicas atreladas ao então ensino de primeiro e segundo graus, dentre as quais a de delegar funções para Conselhos no âmbito dos municípios que viessem, mediante autorização do CEE, a instituí-los (Brasil, 1971). A partir da formulação dada pela Lei n. 5.692/1971, os CEEs passam a distinguir-se nas suas funções do CFE e a identificar-se mais com as funções específicas atinentes aos graus de ensino sob sua responsabilidade normativa, bem como identificar-se também com as demandas da administração da educação no âmbito estadual e municipal. A evidência mais explícita desse distanciamento, em termos legislativos, está na reformulação dos dispositivos da Lei n. 4.024/1961 que criaram o CFE (Brasil, 1961, arts. 6º $7^{\circ}$, $8^{\circ}$ e 9o). Nesta reformulação, que se deu por meio da Lei 9.131, de 24 de novembro de 1995 (Brasil, 1995) ${ }^{5}$, não há nenhuma menção aos CEEs, como havia amplamente nos dispositivos originais da Lei n. 4.024/1961 modificados.

O distanciamento nos textos normativos entre os CEEs e o CNE representou um enfraquecimento do estatuto jurídico dos CEEs em âmbito nacional. Isto ocorre de forma contundente na atual Lei de Diretrizes e Bases da Educação Nacional (LDBEN) - Lei n. 9.394/1996 -, que não menciona a sua existência (Brasil, 1996a). Enquanto a Lei n. 5.691/1971 (Brasil, 1971) dispunha sobre conselhos de educação de modo genérico, sem explicitar a esfera estadual na sua denominação, a Lei n. 9.394/1996 amplia essa generalização ao apenas deixar implícita a sua atuação, isto quando faz referência aos órgãos e instituições dos sistemas de ensino, ao dispor sobre as incumbências dos estados (Brasil, 1996a, art. 10, I). Embora nesse mesmo ano, 1996, os CEEs tenham sido identificados no contexto das regras estabelecidas para a composição dos Conselhos de 
Acompanhamento e Controle Social (CACS) do Fundo de Manutenção e Desenvolvimento do Ensino Fundamental e de Valorização do Magistério (FUNDEF), por meio da Lei n. 9.424, de 24 de dezembro de 1996 (Brasil, 1996b) ${ }^{6}$, o vácuo normativo na legislação federal sobre o papel daquele Conselho e suas respectivas atribuições foi estabelecido e se mantém.

O CNE, por meio do Parecer n. 05, de 7 de maio de 1997 (Brasil, 1997), entendeu que a omissão sobre os CEEs, e também sobre os Conselhos Municipais de Educação (CMEs), no texto da Lei n. 9.394/1996, deveu-se à intenção dos legisladores de respeitar a autonomia legislativa dos entes federados subnacionais para dispor sobre seus órgãos normativos. Reconhece, entretanto, contradição entre a Lei n. 9.394/1196 (Brasil, 1996a) e a que cria o FUNDEF, Lei 9.424/1996 (Brasil, 1996b), pois, nesta última, esse princípio teria sido adotado quando da inclusão dos CEEs como órgãos do sistema estadual a ser representado nos conselhos de acompanhamento e controle social do FUNDEF, conforme referido acima (Brasil, 1997). Além desta contradição apontada no próprio Parecer n. 05/1997, o fato de a maioria dos estados já terem criado os respectivos CEEs na década de 1960, e tê-los em pleno funcionamento na década de 1990, bem como a maioria constituições estaduais vigentes naquela época também já terem definido os CEEs como órgãos normativos dos seus respectivos sistemas de ensino (Cury, 2001), mostra que os estados da federação, no exercício da sua autonomia, haviam feito, há décadas, sua opção pelos CEEs,

A primeira experiência de conselho de educação na administração pública é a do CEE da Bahia, em funcionamento a partir de 1842 (Boaventura, 1992). Entretanto, excetuando esse caso, é no período republicano, principalmente entre os anos de 1962 e $1966^{7}$, que serão criados os CEEs, articulados à organização federativa da educação no Brasil (Câmara, 2016). Não há literatura abundante, entretanto, que informe sobre o funcionamento dos CEEs, sua história e atuação. Não obstante a longevidade desses órgãos, a literatura acadêmica a respeito dos mesmos não é extensa e se encontra preponderantemente em dissertações de mestrado e teses de doutorado que abordam casos de CEEs em períodos delimitados e coincidentes com sua criação ou atuação em governos específicos, como exemplificam os estudos sobre os CEEs do Ceará (Lima, 2013), Distrito Federal (Oliveira, 2013), Mato Grosso do Sul (Bigarella, 2015; Garcia, 2004), Paraíba (Elias Sobrinho, 2007), Paraná (Pelisser, 2008), Rio de Janeiro (Aquino, 2009), São Paulo (Garrossino, 2007), Santa Catarina (Valle, 1991) e Tocantins (Lima, 2006). Esses trabalhos possibilitam compreender, com maior ou menor ênfase, que os efeitos da Lei n. 4.024/1961 (Brasil, 1961) sobre a constituição autônoma dos CEEs, articulados à ação do CFE, foi interrompida pelo golpe militar de 31 de março de 1964 que, por meio da Lei n. 5.692/1971 (Brasil, 1971), imprimiu caráter burocrático e tecnicista a boa parte dos mesmos ${ }^{8}$. É o caso, por exemplo, do CEE de Santa Catarina que, conforme Valle (1991), passa de uma instância político-decisória, especialmente considerando a sua atuação entre os anos de 1962 e 1970, para se configurar, a partir 
de então, como uma instância técnico-burocrática subordinada ao Executivo Estadual.

Esse enfraquecimento dos CEEs frente ao Executivo Estadual aludido no estudo de Valle (1991) é constatado também na atuação recente do CEE do Mato Grosso do Sul, pois, segundo Bigarella (2015, p. 223), esse conselho teria abandonado, inclusive, suas “[...] tarefas de natureza operacional, de emitir atos para credenciar, autorizar o funcionamento de etapas da educação básica, de cursos de educação entre outras as instituições integrantes do Sistema Estadual de Ensino", restringindo sua ação à regulamentação das decisões governamentais anteriormente tomadas e desempenhando um papel de assessoria ao poder Executivo Estadual (Garcia, 2004). Processo semelhante ocorreu também recentemente no estado do Paraná, onde o CEE teria abandonado, do mesmo modo, sua responsabilidade na esfera da organização, formulação e avaliação "[...] das políticas educacionais para tornar-se órgão burocrático onde preponderou o controle do Poder Executivo pelos interesses político-econômicos e privatistas que interferiram na nomeação e recondução dos conselheiros" (Pelisser, 2008, p. 157).

A influência do setor privado na composição e atuação dos CEEs é, também, um elemento relevante nas análises empreendidas sobre esses órgãos. Aborda-se, dentre outros, o efeito do Decreto-Lei n. 532, de 16 de abril de 1969 (Brasil, 1969), que atribui competência aos CEEs, bem como ao CFE, para fixar e reajustar as mensalidades escolares e demais taxas relativas ao serviço prestado pelo setor privado. Essa competência atribuída pelo referido decreto teria atraído o interesse de representantes do setor privado pelos CEEs, os quais passaram a compor efetivamente os mesmos e a influenciar a sua atuação (Lima, 2013; Bigarella, 2015; Elias Sobrinho, 2007). Ocorreu no interior dos CEEs nesse período, segundo Teles (2001), uma consolidação dos interesses privados. Esse efeito parece ter ultrapassado os limites do período histórico compreendido na vigência do Decreto Lei n. 532/1969 e ainda se manter, pelo menos, no caso do CEE de São Paulo onde, conforme estudo divulgado pelo Observatório da Educação da Ação Educação, em 2012, 59\% dos conselheiros estavam ligados à iniciativa privada (Ação Educativa, 2012).

Apesar da presença nos CEEs de uma atuação com traços cartoriais, voltada destacadamente para processos administrativos destinados à autorização e funcionamento de escolas e cursos (Garcia, 2004), os preceitos da gestão democrática, conforme dispõe a Constituição Federal de 1988 (Brasil, 1988), têm influenciado a atuação desses conselhos de modo a introduzir novas práticas com vistas à sua aproximação da condição de gestor das políticas públicas de educação. É o que relataram alguns conselheiros durante a XLIV Plenária Nacional do Fórum dos Conselhos Estaduais de Educação, realizada em 2015, cuja temática foi a sistematização de experiências dos CEEs. Nos anais desse evento, os conselheiros do CEE de Alagoas, por exemplo, se referem às práticas referentes à introdução das temáticas relativas à diversidade na agenda do referido conselho (Bezerra et al., 2015), bem como a presidente do 
CEE de Rondônia também se refere à participação desse órgão na elaboração do PEE local e ao apoio à elaboração dos Planos Municipais de Educação (PMEs), destacando-os como uma construção coletiva (Silva, 2015).

Nesse contexto, finalmente, é compreensível que o papel atribuído a cada um dos CEEs no âmbito dos PEEs apresente considerável variação. Conforme será mostrado a seguir, por um lado, não há norma federal que estabeleça atribuições comuns para os mesmos e, por outro, as experiências locais parecem influenciadas por um passado ainda não totalmente superado vis a vis aos preceitos da gestão democrática.

\section{A Institucionalização dos Novos Planos Estaduais de Educação}

Até o fim de julho de 2016, apenas dois (8\%) dos 26 estados brasileiros não possuíam PEEs consoantes ao PNE 2014-2024 transformados em norma jurídica, todos da Região Sudeste, a saber, Minas Gerais e Rio de Janeiro. De acordo com dados constantes da página do $\mathrm{MEC}^{9}$, o estado de Minas Gerais ainda se encontrava com o seu plano em trâmite na Assembleia Legislativa; enquanto que o Rio de Janeiro possuía, unicamente, o documento base do plano elaborado.

Cabe ainda destacar que o plano do estado do Mato Grosso publicado no seu Diário Oficial possui apenas 17 metas (Mato Grosso, 2014), omitindo, portanto, as Metas 18, 19 e 20 do PNE 2014-2024 (Brasil, 2014) relacionadas, respectivamente, aos planos de carreira dos profissionais da educação, à efetivação da gestão democrática e, ainda, à ampliação do investimento público em educação, expondo, neste caso, nítido desalinhamento em relação a este novo PNE. Já os PEEs do Amazonas e Rondônia vieram a ter as suas leis publicadas nos Diários Oficiais correspondentes, mas sem o texto do plano, cuja edição eletrônica é possível de ser encontrada como documento avulso, apenas apensado à versão eletrônica do órgão oficial do estado (Amazonas, 2015; Rondônia, 2015).

No que concerne aos PEEs efetivamente aprovados, cujo enquadramento legal encontra-se indicado no Quadro 1, curiosamente verifica-se que estados como o Maranhão, Mato Grosso e Mato Grosso do Sul vieram a ter os seus respectivos PEEs aprovados em curtíssimo espaço tempo em relação à sanção do PNE 2014-2024, os dois primeiros, inclusive, alguns dias antes da aprovação deste plano, em 25 junho de 2014, enquanto que o terceiro seis meses após. Tal aspecto põe em dúvida a elaboração democrática desses três planos, no sentido de terem resultado de discussões e deliberações pautadas no texto efetivamente aprovado deste novo PNE, envolvendo "[...] ampla participação de representantes da comunidade educacional e da sociedade civil”, conforme determinado na Lei n. 13.005/2014 (Brasil, 2014, $§ 2^{\circ}$ ). Além disto, sugerem portar desalinhamentos também em relação a este novo PNE, na medida em que podem não ter contemplado, em efetivo, o conteúdo de suas metas e estratégias, tendo-se pautado, possivelmente, em algumas das versões que transitaram no Congresso Nacional.

676 Educação \& Realidade, Porto Alegre, v. 43, n. 2, p. 669-690, abr./jun. 2018. 
Por outro lado, cerca da metade desses 24 estados - 12 (50\%) - veio a ter os seus planos aprovados em 2015, algum tempo após a aprovação do PNE 2014-2024, notadamente dentro do prazo previsto também no art. $8^{\circ}$ desta lei, qual seja, de um ano contado a partir da publicação desta lei - até fins de julho de 2015 (Brasil, 2014). Ainda em 2015, mas com retardos de cerca de dois meses em relação ao prazo legal, nota-se a aprovação dos PEEs de Roraima e Sergipe, seguidos dos planos de Santa Catarina e do Piauí, estes, aproximadamente, com seis meses de atraso. Os demais planos vieram a ser aprovados apenas em 2016, a saber, Alagoas, Rio Grande do Norte, Bahia, Ceará e São Paulo, os dois primeiros com atraso de seis meses, os dois seguintes com dez meses, enquanto que o último plano com um ano de retardo, denotando desalinhamentos temporais iniciais em relação àquele novo PNE.

\section{Quadro 1 - Enquadramento Legal dos PEEs Alinhados ao PNE} 2014-2024 - Junho 2016

\begin{tabular}{|c|c|c|c|}
\hline REFERÊNCIA PEE & $\begin{array}{c}\text { LEI } \\
\mathrm{N} .\end{array}$ & DATA DE APROVAÇÃO & $\begin{array}{c}\text { PERÍODO DE } \\
\text { VIGÊNCIA }\end{array}$ \\
\hline Acre (2015) & 2.965 & 2 de julho de 2015 & $2015-2024$ \\
\hline Alagoas (2016) & 7.795 & 22 de janeiro de 2016 & $2016-2026^{(*)}$ \\
\hline Amapá (2015) & 1.907 & 24 de junho de 2015 & $2015-2025$ \\
\hline Amazonas (2015) & 4.183 & 26 de junho de 2015 & $2015-2025^{(*)}$ \\
\hline Bahia (2016) & 13.559 & 11 de maio de 2016 & $2016-2026^{(*)}$ \\
\hline Ceará (2016) & 16.025 & 30 de maio de 2016 & $2016-2024$ \\
\hline Espírito Santo (2015) & 10.382 & 24 de junho de 2015 & $2015-2025$ \\
\hline Goiás (2015) & 18.969 & 22 de julho de 2015 & $2015-2025$ \\
\hline Maranhão (2014) & 10.099 & 11 de junho de 2014 & $2014-{ }^{(* *)}$ \\
\hline Mato Grosso (2014) & 10.111 & 06 de junho de 2014 & $2014-\left({ }^{(*)}\right.$ \\
\hline Mato Grosso do Sul (2014) & 4.621 & 22 de dezembro de 2014 & $2014-2024^{(*)}$ \\
\hline Pará (2015) & 8.186 & 23 de junho de 2015 & $2015-2025^{(*)}$ \\
\hline Paraíba (2015) & 10.488 & 23 de junho de 2015 & $2015-2025^{(*)}$ \\
\hline Paraná (2015) & 9.479 & 24 de junho de 2015 & $2015-2025$ \\
\hline Pernambuco (2015) & 15.533 & 23 de junho de 2015 & $2015-2025^{(*)}$ \\
\hline Piauí (2015) & 6.733 & 17 de dezembro de 2015 & $2015-2025^{(*)}$ \\
\hline Rio Grande do Norte (2016) & 10.049 & 27 de janeiro de 2016 & 2015-2025 \\
\hline Rio Grande do Sul (2015) & 13.005 & 25 de junho de 2015 & $2015-2025^{(*)}$ \\
\hline Rondônia (2015) & 3.565 & 3 de junho de 2015 & $2014-2024$ \\
\hline Roraima (2015) & 1.008 & 3 de setembro de 2015 & 2014-2024 \\
\hline Santa Catarina (2015) & 16.794 & 14 de dezembro de 2015 & $2015-2024$ \\
\hline São Paulo (2016) & 16.279 & 8 de julho de 2016 & $2016-2026^{(*)}$ \\
\hline Sergipe (2015) & 8.025 & 04 de setembro de 2015 & $2015-2025^{(*)}$ \\
\hline Tocantins (2015) & 2.977 & 8 de julho de 2015 & $2015-2025$ \\
\hline
\end{tabular}

Fonte: Elaborado pelos autores.

(*) Período não explicitado na lei e nem no documento do PEE correspondente, deduzido a partir da data de publicação do plano e da indicação do seu prazo de vigência (para todos os casos, decenal).

${ }^{(* *)}$ Período não explicitado na lei e nem no documento do PEE correspondente, sem possibilidade de ser deduzido a partir da data de publicação do plano por não haver indicação do seu prazo de vigência. 
Ainda com base no Quadro 1, é possível inferir que praticamente a metade desses PEEs - 11 (46\%) - explicita em seus documentos (na lei ou no plano propriamente dito) o intervalo de tempo de sua duração, enquanto que uma segunda fração - $11(46 \%)$ - apenas assinala que o plano vigorará a partir da data de sua publicação, como de praxe dos textos legislativos, tendo-se deduzido o período em questão considerando a data de publicação do PEE e a indicação do tempo total de vigência explicitado (dez anos). Somente dois planos (8\%), Maranhão e Mato Grosso, não permitiram fixar este intervalo de tempo por não constar em seus documentos qualquer determinação do prazo total de duração do PEE.

Todavia, notam-se algumas variações relativas à notação empregada para o período de duração de alguns desses planos, nomeadamente os do Acre e de Santa Catarina. Ambos os planos indicam o período de vigência 2015-2024 na própria ementa da respectiva lei - Aprova o Plano Estadual de Educação para o decênio 2015-2024 [...] (Acre, 2015; Santa Catarina, 2015) -, incluindo na contagem do decênio, portanto, o ano de publicação do plano propriamente dito. Nestes termos, baseiam-se na notação empregada no PNE 2001-2010 e não na adotada pelo PNE 20142024, plano ao qual deveriam expor coesão.

Já os planos do Rio Grande do Norte, Roraima e Rondônia expõem inconsistências em relação aos períodos de vigência exibidos nos seus documentos. Embora o primeiro e o segundo PEEs explicitem na ementa de suas leis que se tratam de planos para o período, respectivamente, 2015-2025 e 2014-2024, ao lado do terceiro PEE que indica no documento do plano apensado à sua lei que o intervalo de tempo corresponde a 2014-2024, todos vieram a ser aprovados somente em 2016. Isto implica considerar que o PEE do Rio Grande do Norte possui duração de nove anos, enquanto que os planos de Roraima e Rondônia oito anos de vigência, não se tratando, portanto, de planos efetivamente decenais, e que principiam com defasagens de tempo significativas em relação ao PNE 2014-2024.

\section{O Papel Atribuído aos Conselhos Estaduais de Educação no Âmbito dos Planos Estaduais de Educação}

Nesta seção, inicialmente averígua-se o papel eventualmente atribuído pelos PEEs aos CEEs ao longo processo de elaboração do plano propriamente dito para. Em seguida, enfoca-se o papel desses órgãos a partir das suas competências institucionais, assim como as indicações de aporte do sistema de ensino para a sua infraestrutura.

Do conjunto dos 24 PEEs sob análise, apenas sete (30\%) fornecem referências a respeito do seu processo de elaboração no estado correspondente. De forma pontual e diminuta, é possível distingui-las nos planos do Acre (2015), Amazonas (2015) e o Paraná (2015). De modo sistematizado, com pormenores e em seções específicas destinadas ao registro desses históricos, essas referências constam dos planos de Goiás (2015), Pará (2015), Paraíba (2015) e Rondônia (2015).

678 Educação \& Realidade, Porto Alegre, v. 43, n. 2, p. 669-690, abr./jun. 2018. 
Em que pese à escassez de informações relativas ao primeiro grupo de PEEs acima mencionado, é possível identificar no documento relativo ao Acre (2015) a ressalva de que o CEE se fez representar neste processo, embora a sua coordenação estivesse a cargo do Fórum Estadual de Educação (FEE). Já nos planos do Amazonas (2015) e do Paraná (2015) não constam referências a este tipo de atuação do CEE.

Por sua vez, Goiás (2015) indica que o FEE, a SEDUC e o CEE foram os responsáveis pela mobilização de “[...] órgãos e instituições vinculadas direta e indiretamente à educação, para dar continuidade ao trabalho de construção coletiva do PEE” (Goiás, 2015, p. 6), aludindo ao processo de adequação do plano anterior ao novo PNE. Esclarece, ainda, acerca do processo de sua discussão e das etapas de elaboração coletiva cumpridas, pormenorizando datas e tempos correlatos. Destaca o caráter democrático e participativo que "[...] permitiu que a população goiana participasse ativamente desse processo” (Goiás, 2015, p. 7), isto ao lado de "[...] quarenta (40) Subsecretarias Regionais de Educação [...] em todos os duzentos e quarenta e seis (246) municípios, realizando quarenta (40) Audiências Públicas" (Goiás, 2015, p. 7).

O PEE do Pará (2015) disponibiliza importantes informações sobre o desenvolvimento do PEE na seção relativa aos agradecimentos, de autoria da Coordenadora do FEE, assim como na seção intitulada Processo para a construção do Plano Estadual de Educação. Sublinha que a construção do plano foi legitimada "[...] por meio da participação e envolvimento da sociedade civil organizada” (Pará, 2015, p. 2), sendo o FEE, o CEE e a SEDUC os seus precursores, com destaque para o primeiro órgão no sentido de ter possibilitado "[...] a democratização do processo de construção das políticas educacionais no Estado do Pará” (Pará, 2015, p. 2). Apesar da brevidade do texto relativo a estas informações, indica que o plano adveio da atuação do poder público, ao lado da participação da sociedade civil, tendo implicado, entre outros, "[...] 123 conferências municipais, 12 conferências regionais e a conferência estadual" (Pará, 2015, p. 6), também datando o conjunto de atividades mencionadas.

Já o plano da Paraíba (2015), do mesmo modo que os dois PEEs acima destacados, remete ao processo em questão tanto na sua apresentação, quanto em uma extensa seção destinada a este fim, intitulada Plano Estadual de Educação: um projeto de todos/as e para todos/as. Indica que o PEE foi construído sob coordenação do CEE, ao lado de "[...] 90 pessoas envolvidas nas comissões temáticas, formadas por representantes de sindicatos, conselhos, universidades, escolas, instituições públicas e privadas de ensino e de movimentos sociais" (Paraíba, 2015, p. 1). A elaboração do plano é esmiuçada, também incorporando datas e a indicação do ordenamento normativo que veio a regulamentá-lo no território.

Ainda no que se refere a essas formulações, o PEE de Rondônia, não diferentemente dos planos precedentes, ilustra a apresentação do documento com alguns detalhes sobre a sua elaboração, sendo seguido de seção intitulada O processo de elaboração do Plano Estadual de Edu- 
cação-PEE/RO. Ressalta que a coordenação do processo de construção coletiva do PEE foi assumida pelo FEE e pela SEDUC, tendo sido responsáveis pelo convite de parceiros, pela mobilização de vários segmentos sociais, pelas discussões metodológicas que permearam as etapas de sua elaboração, “[...] cujo conteúdo final é resultado de discussões e deliberações legitimadas em treze Conferências Regionais e na Conferência Estadual de Educação" (Rondônia, 2015, p. 10). Esclarece, ainda, que o plano "[...] foi construído com amplo processo democrático envolvendo a participação efetiva dos Sistemas de Ensino, Representações dos Poderes Executivo e Legislativo, Ministério Público, Sociedade Civil e Entidades Colegiadas [...]" (Rondônia, 2015, p. 10). A descrição do seu processo de elaboração ocorre com detalhes relativos a datas, prazos e ao ordenamento normativo correlato, também indicando as etapas cumpridas.

No seu conjunto, as informações disponíveis sobre a elaboração desses PEEs não destacam o papel dos CEEs na sua formulação, a exceção do PEE da Paraíba (2015) que, conforme mencionado, teve esse órgão como coordenador do processo de elaboração ocorrido naquele Estado. Do mesmo modo, as leis de criação dos referidos planos, incluindo os respectivos anexos em que constam as suas metas e estratégias, também não destacam os CEEs como protagonistas da implementação dos mesmos.

Contudo, outras referências aos CEEs são apresentadas nesses documentos, podendo ser classificadas por meio de duas temáticas: competências e infraestrutura. Na primeira temática, relativa à competência dos CEEs, foram identificadas referências relativas às seguintes categorias: i) fiscalização e controle, ii) normatização e iii) assessoramento. Quanto à segunda temática, relativa à infraestrutura, as categorias referenciadas foram: i) organização interna, ii) financiamento dos CEEs e iii) formação de conselheiros.

Os CEEs foram mencionados 104 vezes no conjunto dos 24 PEEs analisados, das quais $75(72 \%)$ foram para se referir às suas competências e $29(28 \%)$ vezes à sua infraestrutura, conforme mostra o Quadro 2. A competência com maior frequência foi a de fiscalização e controle (35\%), seguida da competência de normatização (23\%) e assessoramento (15\%). Apenas 6 (26\%) PEEs atribuem 5 (5\%) ou mais competências aos CEEs locais, sendo que o PEE do Mato Grosso (2014) não menciona esse órgão. 


\section{Quadro 2 - Frequência das Competências e da Definição de Infraestrutura Atribuídas aos CEEs nos PEEs Alinhados ao PNE 2014-2014, por Categoria - 2016}

\begin{tabular}{|c|c|c|c|c|c|c|c|}
\hline \multirow{2}{*}{$\begin{array}{l}\text { TEMA/ } \\
\text { CATEGORIA/ } \\
\text { ESTADO }\end{array}$} & \multicolumn{3}{|c|}{ COMPETENCIAS } & \multicolumn{3}{|c|}{ INFRAESTRUTURA } & \multirow[b]{2}{*}{ TOTAL } \\
\hline & $\begin{array}{l}\text { FISC./ } \\
\text { CONT. }^{(1)}\end{array}$ & $\underset{\text { (2) }}{\mathrm{NORM}}$ & $\underset{(3)}{\operatorname{ASSES}}$ & $\underset{(4)}{\mathrm{ORG}}$ & $\underset{(5)}{\text { FIN. }}$ & $\underset{(6)}{\text { FORM. }}$ & \\
\hline Acre & 01 & - & - & - & 01 & - & 02 \\
\hline Alagoas & 02 & 01 & - & - & - & - & 03 \\
\hline Amapá & 02 & - & - & - & - & 01 & 03 \\
\hline Amazonas & - & - & - & - & - & - & 00 \\
\hline Bahia & 01 & 09 & 07 & - & - & - & 17 \\
\hline Ceará & 03 & 01 & 02 & - & - & - & 06 \\
\hline Espírito Santo & 01 & - & - & - & - & - & 01 \\
\hline Goiás & 03 & - & 01 & - & - & - & 04 \\
\hline Maranhão & - & - & - & 02 & - & - & 02 \\
\hline Mato Grosso & - & - & - & - & - & - & - \\
\hline Mato Grosso do Sul & 01 & - & - & 01 & 01 & 01 & 04 \\
\hline Pará & 01 & - & - & - & - & 01 & 02 \\
\hline Paraíba & 01 & - & - & - & - & 01 & 02 \\
\hline Paraná & 01 & - & 01 & - & - & 01 & 03 \\
\hline Pernambuco & - & - & - & - & 02 & - & 02 \\
\hline Piauí & 01 & 01 & - & 01 & 01 & 02 & 06 \\
\hline $\begin{array}{l}\text { Rio Grande do } \\
\text { Norte }\end{array}$ & 03 & 01 & - & - & 02 & 01 & 07 \\
\hline Rio Grande do Sul & 07 & 04 & 03 & - & - & 01 & 15 \\
\hline Rondônia & - & 02 & - & - & - & - & 02 \\
\hline Roraima & 01 & - & - & 01 & 01 & - & 03 \\
\hline Santa Catarina & 01 & - & - & 01 & - & - & 02 \\
\hline Sergipe & 02 & 04 & - & 01 & - & 02 & 09 \\
\hline São Paulo & 01 & - & 02 & 01 & - & - & - \\
\hline Tocantins & 03 & - & - & 01 & - & 01 & 05 \\
\hline SUBTOTAL & 36 & 23 & 16 & 09 & 08 & 12 & 104 \\
\hline TOTAL & & & 75 & & & 29 & 104 \\
\hline
\end{tabular}

Fonte: Elaborado pelos autores.

OBS.: (1) Fiscalização/Controle, (2) Normatização, (3) Assessoramento, (4) Organização, (5) Financiamento, (6) Formação.

A competência de fiscalização e controle dos CEEs foi identificada em 19 (79\%) dos PEEs analisados (conforme Quadro 2), com uma frequência de 36 (35\%) vezes. No âmbito desta competência, a atribuição de monitorar e avaliar o cumprimento das metas e estratégias do próprio PEE do respectivo estado representa mais da metade (57\%) dos dispositivos que reproduzem, por vezes literalmente, ou com poucas variações, o texto do PNE 2014-2024 quando o mesmo se refere ao papel do CNE, de forma compartilhada com outras instâncias, em relação à ação de monitorar e avaliar o PNE (Brasil, 2010). Além disso, nesta categoria estão agrupadas também outras atribuições específicas dos CEEs, tais como 
Conselhos Estaduais de Educação nos Novos Planos Estaduais de Educação

regularização e reconhecimento de estabelecimentos de ensino públicos e, sobretudo, privados. No caso do PEE do Rio Grande do Sul (2015), destaca-se o papel atribuído ao CEE para fiscalizar a implementação pela SEDUC de políticas estaduais tais como as políticas de acessibilidade, a aplicação dos recursos destinados ao gasto público com educação, a garantia da oferta de educação em territórios quilombolas, o cumprimento da legislação que prevê diálogo dos sistemas de ensino com o movimento negro, assim como a fiscalização da presença de especialistas nas escolas e agências de formação oriundos das comunidades tradicionais quilombolas.

A competência de normatização, segunda com maior frequência no conjunto dos PEEs, foi mencionada em apenas 8 (35\%) dos PEEs analisados (conforme Quadro 2), sendo que somente no PEE da Bahia (2016) constam 9 (39\%) dispositivos a esse respeito, e no PEE do Rio Grande do Sul (2015) e Sergipe (2015) constam 4 (17\%) dispositivos agrupados nesta categoria em cada um. Considerada a competência mais nobre e importante atribuída aos conselhos de educação, a função normativa é, segundo Cury (2006, p. 42), “[...] aquela que dá a verdadeira distinção de um Conselho de Educação”. Neste sentido, destaca-se o PEE da Bahia (2016), que atribui ao CEE competências para normatizar desde a organização e funcionamento das instituições de Educação Infantil, Ensino Fundamental e Ensino Médio - incluindo prerrogativas relativas à sua organização curricular - até a competência para normatizar os planos de carreira dos profissionais da Educação Básica da rede particular deste nível de ensino. A competência normativa atribuída pelo PEE da Bahia (2016) ao CEE enfatiza, ainda, a ação desse órgão em relação aos temas relativos à diversidade e ao respeito aos direitos humanos, bem como aqueles relativos à garantia do direito de aprender, inclusive para os jovens e adultos. Esse papel normativo é destaque em relação aos demais cinco PEEs que, quando incluem essa função, o fazem, preponderantemente, por meio das atribuições relativas à regulamentação da oferta do ensino privado e à organização cotidiana dos Sistemas Estaduais de Ensino ${ }^{10}$.

O assessoramento, competência inserida em 6 (25\%) dos planos analisados (conforme Quadro 2), teve maior frequência no PEE da Bahia (2016), que atribui ao CEE as prerrogativas de fomentar e subsidiar a elaboração de diretrizes e orientações para organização e funcionamento das instituições de educação infantil; receber propostas de direitos e objetivos de aprendizagens para o ensino fundamental; dar aval aos indicadores de qualidade definidos pela secretaria de educação, em comum acordo com os conselhos municipais de educação, para o funcionamento de instituições de ensino públicas e privadas que prestam atendimento a estudantes com deficiência, transtornos globais do desenvolvimento e altas habilidades; discutir novos formatos para o reconhecimento dos cursos de Graduação das universidades estaduais; e, por fim, dar aval à definição de áreas prioritárias no âmbito da política estadual de formação de docentes da educação básica. Os PEEs do Ceará (2016), Paraná (2015) e Rio Grande do Sul (2015) mencionam

682 Educação \& Realidade, Porto Alegre, v. 43, n. 2, p. 669-690, abr./jun. 2018. 
também a competência de assessoramento aos CMEs, com vistas tanto à sua criação quanto ao seu fortalecimento e consolidação.

A definição de infraestrutura para os CEEs foi regulamentada em 16 (67\%) dos PEEs analisados (conforme Quadro 2), seja por meio das referências ao financiamento dos mesmos, à sua organização ou à formação dos conselheiros. Entre estas referências, a que obteve a maior frequência (12\%) foi a formação de conselheiros. Entretanto, a maioria dos PEEs aborda essa formação no contexto dos demais Conselhos de políticas públicas de educação, inserindo os CEEs ao lado destes, sem destaque para as suas especificidades. A garantia de recursos financeiros para o funcionamento dos CEEs é mencionada em apenas 6 (25\%) dos PEEs analisados, todos de forma inespecífica, sem detalhar a proporção ou periodicidade de repasse desses recursos. Ainda no que se refere à infraestrutura, por fim, a organização dos CEEs foi mencionada em 8 (33\%) PEEs. Destacam-se, entre estes, aqueles que dispõem sobre a composição dos CEEs para garantir representação no âmbito deste órgão de segmentos tais como a educação profissional (Roraima, 2015), a educação do campo (Santa Catarina, 2015), a educação afro-brasileira e quilombola (Tocantins, 2015), bem como a representação de professores e gestores das escolas proporcionalmente ao número de alunos matriculados nas mesmas (Sergipe, 2015).

\section{Conclusões}

Os CEEs apresentam uma trajetória declinante, desde a sua criação, se considerarmos o papel dos mesmos no âmbito da educação nacional. Se, originalmente, os princípios presentes na sua institucionalização figuravam na legislação nacional, articulando-os ao CNE e aos propósitos que vinculavam as unidades federadas a um projeto comum de educação, a partir da efetiva criação da maioria desses órgãos, na década de 1960, e da regulamentação subsequente, os CEEs foram paulatinamente omitidos pela legislação nacional. A um só tempo, foram sendo circunscritos ao âmbito dos estados, de onde, aliás, pouco se conhece, no contexto da literatura acadêmica, e mesmo dos debates nacionais, sobre sua organização e funcionamento.

Sabe-se que, sobretudo a partir da consolidação dos CEEs na década de 1970, sobressaiu-se nesses órgãos um perfil de atuação fortemente cartorial e voltado para a regulamentação das instituições privadas de ensino. Porém, a partir das demandas impostas pelo imperativo da gestão democrática, com a Constituição Federal de 1988 e, posteriormente, também com as novas configurações dos sistemas de ensino regulamentadas pela LDBEN de 1996, os CEEs foram, por um lado, impactados pelo esvaziamento de algumas das suas competências e práticas, destacadamente em relação à normatização da educação municipal e, por outro lado, pressionados pelas novas demandas que se apresentaram a partir de então, tais como as que se inscrevem no contexto do planejamento estadual. É o que ocorreu, por exemplo, em relação ao PEEs atualmente alinhados ao PNE 2014-2024, bem como em relação aos planos imediatamente anteriores a estes, consoantes ao PNE 2001-2010. 
Conselhos Estaduais de Educação nos Novos Planos Estaduais de Educação

Sendo a gestão democrática um princípio do planejamento, compreender o papel dos CEEs no movimento de elaboração dos PEEs torna-se lócus privilegiado para evidenciar as experiências recentes desse órgão no exercício das suas competências nos Sistemas Estaduais de Ensino. Assim, quanto à elaboração dos PEEs, nota-se recorrente preocupação em sobrelevar o caráter democrático do processo territorialmente vivido, no qual espaços como os CEEs, ao lado dos FEEs, são expostos como relevantes para o planejamento democrático estadual da educação. Entretanto, não foram identificados elementos significativos quanto ao papel efetivamente desempenhado por esses Conselhos na elaboração dos planos analisados.

A ausência de um protagonismo dos CEEs no processo de elaboração dos PEEs em questão tem reflexos nas leis de criação destes últimos que, uma vez aprovadas, revelaram um esvaziamento das competências dos CEEs como órgãos dos Sistemas Estaduais de Ensino, bem como uma fragilidade no que se refere ao aporte do sistema para sua infraestrutura. A referência ao órgão nessa legislação é escassa e, quando presente, apresenta baixa frequência no conjunto dos PEEs, revelando uma presença subsumida a ações pontuais e pouco articuladas com a natureza de um órgão de Estado. As evidências, assim, parecem indicar, por um lado, a permanência de funções cartoriais, que burocratizam tais conselhos e, por outro, um enfraquecimento dos mesmos no seu poder de atuar como conselho gestor das políticas educacionais no âmbito dos respectivos estados.

Recebido em 13 de julho de 2016 Aprovado em 19 de julho de 2017

\section{Notas}

1 Disponível em: <http://pne.mec.gov.br/planos-de-educacao/situacao-dosplanos-de-educacao>. Acesso em: 29 jul. 2016.

2 Os fundos especiais eram constituídos por sobras das dotações orçamentárias acrescidas das doações, percentagens sobre o produto de vendas de terras públicas, taxas especiais e outros recursos financeiros da União, estados e Distrito Federal destinados para auxílios a alunos necessitados, mediante fornecimento gratuito de material escolar, bolsas de estudo, assistência alimentar, dentária, médica, e para vilegiaturas (Brasil, 1934, art. 157, § 1º, 2º.

3 Contudo, em virtude do golpe de 1937, que culminou no Estado Novo, os recomendados CEEs não foram criados e organizados a contento, nas respectivas unidades da Federação, até a década de 1960. Exceção, em termos normativos, é o estado do Amazonas, que criou o CEE por meio da Constituição Estadual de 1946, e o Rio Grande do Sul, que também previu o CEE na sua Constituição Estadual de 1935. A instalação efetiva deste último, entretanto, ocorreu somente em 1962 (Câmara, 2016). Além disso, conforme Aquino (2009), o Estado do Rio de Janeiro, em 1954 - antes da sua fusão com o Estado da Guanabara, portanto -, teria criado também um CEE. A maioria dos CEEs, todavia, foi criada após a aprovação da Lei n. 4.024/1961 (Brasil, 1961).

4 De acordo com a Lei n. 4.024/1961, o Ensino Médio correspondia a dois ciclos, o ginasial e o colegial, abrangendo, entre outros, os cursos secundários, técnicos e de formação de professores para o ensino primário e pré-primário (Brasil, 1961, art. 34).

684 Educação \& Realidade, Porto Alegre, v. 43, n. 2, p. 669-690, abr./jun. 2018. 
5 A Lei n. 9.131/1995 extingue o CFE e cria o CNE, definindo sua organização e funcionamento (Brasil, 1995).

6 A Lei n. 9.424/1996 estabelece que os Conselhos de Acompanhamento e Controle Social do FUNDEF nos estados serão constituídos por, no mínimo, sete membros, dentre os quais um representante do CEE respectivo (Brasil, 1996b, art. $4^{\circ}, \S 1^{\circ}$, II, C).

7 Antes disso, entretanto, foram criados os CEEs do Rio Grande do Sul, em 1935, e do Amazonas, em 1946. No ano de 1962 foram criados os CEEs de Alagoas, Distrito Federal, Espírito Santo, Goiás, Maranhão, Minas Gerais, Paraíba, Rio Grande do Norte e Santa Catarina. Já os CEEs do Ceará, Mato Grosso, Pará, Pernambuco, Piauí, São Paulo e Sergipe foram criados em 1963 e, no ano seguinte, 1964, os do Acre e do Paraná. Em 1966 foi criado o de Rondônia. Os demais CEEs - Amapá, Rio de Janeiro, Mato Grosso do Sul, Roraima - foram criados posteriormente, respectivamente em 1973, 1975, 1977, 1992 (Câmara, 2016).

8 Exceção é o caso do CEE do Ceará que, segundo Lima (2013), não sofreu influência do regime militar nem na sua composição, nem na sua atuação, que se deu com relativa autonomia na regulamentação da educação na década de 1970.

9 Disponível em: <http://pne.mec.gov.br/planos-de-educacao/situacao-dosplanos-de-educacao >. Acesso em: 29 jul. 2016.

10 Uma exceção relevante em relação a essa competência comum é a que foi estabelecida para o CEE pelo PEE do Ceará (2016), que atribui a esse órgão, ao lado do FEE e da SEDUC, a competência para definir o valor e o conteúdo do Custo Aluno Qualidade (CAQ), a partir da legislação federal.

\section{Referências}

ABICALIL, Carlos Augusto. O Plano Nacional de Educação e o Regime de Colaboração. Revista Retratos da Escola, Brasília, v. 8, n. 15, p. 249-263, jul./dez. 2014.

AÇÃO EDUCATIVA. Maioria do Conselho Estadual de Educação de SP é vinculada ao setor privado. Observatório da Educação, São Paulo, 28 maio 2012. Disponível em: <http://www.correiodobrasil.com.br/maioria-do-conselho-estadual-de-educacao-de-sao-paulo-e-vinculada-ao-setor-privado/>. Acesso em: 23 ago. 2017

ACRE. Lei n. 2.965, de 2 de julho de 2015. Aprova o Plano Estadual de Educação para o decênio 2015-2024 e dá outras providências. Diário Oficial do Estado de Acre, Rio Branco, 03 jul. 2015.

ALAGOAS. Lei n. 7.795, de 22 de janeiro de 2016. Aprova o Plano estadual de Educação PEE, e dá outras providências. Diário Oficial do Estado de Alagoas, Maceió, 25 jan. 2016.

AMAPÁ. Lei n. 1.907, de 24 de junho de 2015. Dispõe sobre o Plano Estadual de Educação - PEE, para o decênio 2015-2025, e dá outras providências. Diário Oficial do Estado do Amapá, Macapá, 24 de junho de 2015.

AMAZONAS. Lei n. 4.183, de 26 de junho de 2015. Aprova o Plano Estadual de Educação do Estado do Amazonas e dá outras providências. Diário Oficial do Estado do Amazonas, Manaus, 26 jun. 2015. 
Conselhos Estaduais de Educação nos Novos Planos Estaduais de Educação

AQUINO, Rosemary Guimarães. Políticas Educacionais Pós-Fusão: a construção do CEE/RJ. 2009. 129 f. Dissertação (Mestrado em Educação) - Faculdade de Educação, Universidade do Estado do Rio de Janeiro, Rio de Janeiro, 2009.

BAHIA. Lei n. 13.559, de 11 de maio de 2016. Aprova o Plano Estadual de Educação da Bahia e dá outras providências. Diário Oficial do Estado da Bahia, Salvador, 12 maio 2016 .

BARDIN, Laurence. Análise de Conteúdo. 4. ed. Lisboa: Edições 70, 2004.

BEZERRA, Sara Jane Cerqueira; COSTA, Jairo José Campos; CAVALCANTE, Luiz Henrique de Oliveira; COSTA E SILVA, Bárbara Heliodora; VIDINHA, Marly do Socorro Peixoto. Normatização Educacional: um permanente diálogo entre o Conselho Estadual de Alagoas e a Sociedade Civil. In: PLENÁRIA NACIONAL DO FÓRUM DOS CONSELHOS ESTADUAIS DE EDUCAÇÃO, 44., 2015, Maceió. Anais... Maceió: 2015. P. 1-13.

BIGARELLA, Nadia. O Papel do Conselho Estadual de Educação de Mato Grosso do Sul na Definição de Políticas de Gestão para a Educação Básica. 2015. 254 f. Tese (Doutorado em Educação) - Universidade Católica Dom Bosco, Campo Grande, 2015.

BOAVENTURA, Edivaldo Machado. Criação e Reorganização do Conselho de Educação da Bahia. Revista Sitientibus, Feira de Santana, n. 10, p. 13-30, jul./ dez. 1992.

BRASIL. Constituição da República dos Estados Unidos do Brasil (de 16 de julho de 1934). Nós, os representantes do povo brasileiro, pondo a nossa confiança em Deus, reunidos em Assembléia Nacional Constituinte para organizar um regime democrático, que assegure à Nação a unidade, a liberdade, a justiça e o bem-estar social e econômico, decretamos e promulgamos a seguinte. Diário Oficial da União, Rio de Janeiro, 16 jul. 1934.

BRASIL. Lei n. 4.024, de 20 de dezembro de 1961. Fixa as diretrizes e bases da educação nacional. Diário Oficial da União, Brasília, 27 dez. 1961.

BRASIL. Conselho Federal de Educação. Separata de Documenta n. 21: relações entre o Conselho Federal de Educação e os Conselhos Estaduais. Série Documenta, Rio de Janeiro, v. 2, n. 21, dez. 1963.

BRASIL. Decreto-Lei n. 532, de 16 de abril de 1969. Dispõe sobre a fixação e o reajustamento de anuidades, taxas e demais contribuições do serviço educacional. Diário Oficial da União, Brasília, 17 abr. 1969.

BRASIL. Lei n. 5.692, de 11 de agosto de 1971. Fixa diretrizes e bases para o ensino de $1^{\circ}$ e $2^{\circ}$ graus, e dá outras providências. Diário Oficial da União, Brasília, 12 ago. 1971.

BRASIL. Constituição da República Federativa do Brasil de 1988. Nós, representantes do povo brasileiro, reunidos em Assembléia Nacional Constituinte para instituir um Estado Democrático, destinado a assegurar o exercício dos direitos sociais e individuais, a liberdade, a segurança, o bem-estar, o desenvolvimento, a igualdade e a justiça como valores supremos de uma sociedade fraterna, pluralista e sem preconceitos, fundada na harmonia social e comprometida, na ordem interna e internacional, com a solução pacífica das controvérsias, promulgamos, sob a proteção de Deus, a seguinte Constituição da República Federativa do Brasil. Diário Oficial da União, Brasília, 5 out. 1988.

BRASIL. Lei n. 9.131, de 24 de novembro de 1995. Altera dispositivos da Lei n. 4.024, de 20 de dezembro de 1961, e dá outras providências. Diário Oficial da União, Brasília, 25 nov. 1995.

686 Educação \& Realidade, Porto Alegre, v. 43, n. 2, p. 669-690, abr./jun. 2018 
BRASIL. Lei n. 9.394, de 20 de dezembro de 1996. Estabelece as Diretrizes e Bases da Educação Nacional. Diário Oficial da União, Brasília, 23 dez. 1996a.

BRASIL. Lei n. 9.424, de 24 de dezembro de 1996. Dispõe sobre o Fundo de Manutenção e Desenvolvimento do Ensino Fundamental e de Valorização do Magistério, na forma prevista no art. $60, \S 7^{\circ}$, do Ato das Disposições Constitucionais Transitórias e dá outras providências. Diário Oficial da União, Brasília, 26 dez. 1996b.

BRASIL. Conselho Nacional de Educação. Câmara de Educação Básica. Parecer n. 5, de 7 de maio de 1997. Proposta de Regulamentação da Lei no 9.394/96. Diário Oficial da União, Brasília, 16 maio 1997.

BRASIL. Lei n. 10.172, de 09 de janeiro de 2001. Aprova o Plano Nacional de Educação (PNE) e dá outras providências. Diário Oficial da União, Brasília, 10 jan. 2001.

BRASIL. Lei n. 12.376, de 30 de dezembro de 2010. Altera a ementa do Decreto-Lei n. 4.657, de 4 de setembro de 1942. Diário Oficial da União, Rio de Janeiro, 31 dez. 2010.

BRASIL. Lei n. 13.005, de 25 de junho de 2014. Aprova o Plano Nacional de Educação - PNE e dá outras providências. Diário Oficial da União, Brasília, 26 jun. 2014.

CÂMARA, Adriane Peixoto. O Papel do Conselho Estadual de Educação na Formulação de Políticas Públicas de Educação no Âmbito do Sistema Estadual de Ensino de Minas Gerais. 2016. 120 f. Relatório de Qualificação (Doutorado em Educação) - Faculdade de Educação, Universidade Federal de Minas Gerais, Belo Horizonte, 2016.

CEARÁ. Lei n. 16.025, 30 de maio de 2016. Dispõe sobre o plano estadual de educação (2016/2024). Diário Oficial do Estado do Ceará, Fortaleza, v. 8, n. 101, 30 maio 2016.

CONSELHO Nacional de Secretários de Educação. Subsídios para os Novos Gestores Estaduais da Educação: 2011-2014. Brasília: CONSED, 2010.

CURY, Carlos Roberto Jamil. Os Conselhos Estaduais de Educação nas Constituições Estaduais Brasileiras. Educação, Legislação e Cidadania, Recife, v. 1, p. 15-33, 2001

CURY, Carlos Roberto Jamil. Conselhos de Educação: fundamentos e funções. Revista Brasileira de Política e Administração da Educação, Rio de Janeiro, v. 22, n. 1, p. 41-67, jan./jun. 2006.

ELIAS SOBRINHO, Severino. O Papel do Conselho Estadual de Educação da Paraíba (CEE/PB) como Órgão Normativo do Sistema Estadual de Ensino no Período de 1962-2002. 2007. 264 f. Dissertação (Mestrado em Educação) - Centro de Educação, Universidade Federal da Paraíba, João Pessoa, 2007.

ESPÍRITO SANTO. Lei n. 10.382, de 24 de junho de 2015. Aprova o Plano estadual de Educação do espírito Santo - PEE/ES, período 2015/2025. Diário Oficial do Estado do Espírito Santo, Vitória, 25 jun. 2015.

GARCIA, Kelly Cristiny de Lima. O Papel do Conselho Estadual de Educação de Mato Grosso do Sul na Definição das Políticas Públicas Setoriais: 1995-2002. 2004. 136 f. Dissertação (Mestrado em Educação) - Universidade Federal do Mato Grosso do Sul, Campo Grande, 2004.

GARROSSINO, Silvia Regina Barboza. A Contribuição de Dermeval Saviani no Conselho Estadual de Educação de São Paulo (1984-1987). 2007. 94 f. Dissertação (Mestrado em Educação) - Faculdade de Filosofia e Ciências, Universidade Estadual Paulista Júlio de Mesquita Filho, São Paulo, 2007. 
Conselhos Estaduais de Educação nos Novos Planos Estaduais de Educação

GOIÁS. Lei n. 18.969, de 22 de julho de 2015. Aprova o Plano Estadual de Educação para o decênio 2015/2025 e dá outras providências. Diário Oficial do Estado de Goiás, Goiânia, 27 jul. 2015.

KETELE, Jean-Marie de; ROEGIERS; Xavier. Metodologia da Recolha de Dados: fundamentos dos métodos de observações, de questionários, de entrevistas e de estudo de documentos. Lisboa: Instituto Piaget, 1993.

LIMA, Jeimes Mazza Correia. Entre dois Agostos: Conselho de Educação do Ceará na década de 1970-1979. 2013. 182 f. Tese (Doutorado em Educação Brasileira) - Faculdade de Educação, Universidade Federal do Ceará, Fortaleza, 2013.

LIMA, Rachel Bernardes de. Conselho Estadual de Educação do Tocantins: sua trajetória e o desafio da autonomia. 2006. 264 f. Dissertação (Mestrado em Educação) - Programa de Pós-Graduação Stricto Sensu em Educação da Universidade Católica de Brasília, Brasília, Distrito Federal, 2006.

MARANHÃO. Lei n. 10.099, de 11 de junho de 2014. Aprova o Plano Estadual de Educação do Estado do Maranhão e dá outras providências. Diário Oficial do Estado do Maranhão, São Luiz, 11 jun. 2014.

MATO GROSSO DO SUL. Lei n. 4.621, de 22 de dezembro de 2014. Aprova o Plano Estadual de Educação de Mato Grosso do Sul, e dá outras providências. Diário Oficial do Estado do Mato Grosso do Sul, Campo Grande, 26 dez. 2014.

MATO GROSSO. Lei n. 10.111, de 06 de junho de 2014. Dispõe sobre a revisão e alteração do Plano Estadual de Educação, instituído pela Lei n. 8.806, de 10 de janeiro de 2008. Diário Oficial do Estado do Mato Grosso, Cuiabá, 06 jun. 2014.

OLIVEIRA, Regina Tomás Blum de. Cidadania, Participação Social, Democracia e Qualidade na Educação: uma análise dos pareceres do Conselho Estadual de Educação do Distrito Federal. 2013. 110 f. Dissertação (Mestrado em Educação) - Universidade Católica de Brasília, Brasília, 2013.

PARÁ. Lei n. 8.186, de 23 de junho de 2015. Aprova o Plano Estadual de Educação - PEE e dá outras providências. Diário Oficial do Estado do Pará, Belém, 24 jun. 2015.

PARAÍBA. Lei n. 10.488, de 23 de junho de 2015. Aprova o Plano Estadual de Educação - PEE e dá outras providências. Diário Oficial do Estado da Paraíba, João Pessoa, 24 jun. 2015.

PARANÁ. Lei n. 18.492, de 24 de junho de 2015. Aprovação do Plano Estadual de Educação e adoção de outras providências. Diário Oficial do Estado do Paraná, Curitiba, 25 jun. 2015.

PELISSER, Joseval Basílio. O Conselho Estadual de Educação na era Lerner: secundação e coonestação das políticas públicas para a Escola Paranaense. 2008. 192 f. Dissertação (Mestrado em Educação) - Universidade Federal do Paraná, Curitiba, 2008.

PERNAMBUCO. Lei n. 15.533, de 23 de junho de 2015. Aprova o Plano Estadual de Educação PEE. Diário Oficial do Estado de Pernambuco, Recife, 24 jun. 2015.

PIAUÍ. Lei n. 6.733, de 17 de dezembro de 2015. Diário Oficial do Estado do Piauí, Teresina, 21 dez. 2015.

RIO GRANDE DO NORTE. Lei n. 10.049, de 27 de janeiro de 2016. Aprova o Plano Estadual de Educação do Rio Grande do Norte (2015-2025) e dá outras providências. Diário Oficial do Estado do Rio Grande do Norte, Natal, 27 jan. 2016.

RIO GRANDE DO SUL. Lei n. 14.705, de 25 de junho de 2015. Institui o Plano Estadual de Educação - PEE -, em cumprimento ao Plano Nacional de Educa-

688 Educação \& Realidade, Porto Alegre, v. 43, n. 2, p. 669-690, abr./jun. 2018. 
ção - PNE -, aprovado pela Lei Federal n. 13.005, de 25 de junho de 2014. Diário Oficial do Estado do Rio Grande do Sul, Porto Alegre, 26 jun. 2015.

RONDÔNIA. Lei n. 3.565, de 3 de junho de 2015. Institui o Plano Estadual de Educação de Rondônia. Diário Oficial do Estado de Rondônia, Porto Velho, 3 de junho de 2015.

RORAIMA. Lei n. 1.008, de 3 de setembro de 2015. Aprova o Plano Estadual de Educação 2014-2024 (PEE) e dá outras providências. Diário Oficial do Estado de Roraima, Boa Vista, 3 de setembro de 2015.

SANTA CATARINA. Lei n. 16.794, de 14 de dezembro de 2015. Aprova o Plano Estadual de Educação (PEE) para o decênio 2015-2024 e estabelece outras providências. Diário Oficial do Estado de Santa Catarina, Florianópolis, 15 de dezembro de 2015.

SÃO PAULO (Estado). Lei n. 16.279, de 8 de julho de 2016. Aprova o Plano Estadual de Educação de São Paulo e dá outras providências. Diário Oficial do Estado de São Paulo, São Paulo, 09 jul. 2016.

SERGIPE. Lei n. 8.025, de 04 de setembro de 2015. Dispõe sobre o Plano Estadual de Educação - PEE, e dá providências correlatas. Diário Oficial do Estado de Sergipe, Aracajú, 08 set. 2015.

SILVA, Francisca Batista da. O Papel do Conselho Estadual de Educação no Sistema Estadual de Ensino de Rondônia. In: PLENÁRIA NACIONAL DO FÓRUM DOS CONSELHOS ESTADUAIS DE EDUCAÇÃO, 44., 2015, Maceió. Anais... Maceió: 2015. P. 1-15.

SOUZA, Donaldo Bello de; MENEZES, Janaína Specht da Silva. Elaboração e Aprovação de Planos de Educação no Brasil: do nacional ao local. Ensaio - Avaliação e Políticas Públicas em Educação, Rio de Janeiro, v. 23, n. 89, p. 901-936, 2015.

SOUZA, Donaldo Bello de; MENEZES, Janaína Specht da Silva. Acompanhamento e Avaliação dos/nos Planos Estaduais de Educação 2001-2010. Educação \& Realidade, Porto Alegre, v. 41, n. 2, p. 313-334, 2016.

TELES, Rosângela Mendonça. O Papel dos Conselhos de Educação na Formação dos Sistemas Educacionais Brasileiros. In: REUNIÃO ANUAL DA ASSOCIAÇÃO NACIONAL DE PÓS-GRADUAÇÃO E PESQUISA EM EDUCAÇÃO, 24., 2001, Caxambu. Anais... Caxambu: 2001. P. 1-9. Disponível em <http://24reuniao.anped. org.br/tp.htm>. Acesso em: 29 ago. 2017.

TOCANTINS. Lei n. 2.977, de 8 de julho de 2015. Aprova o Plano Estadual de Educação do Tocantins - PEE/TO (2015-2025), e adota outras providências. Diário Oficial do Estado do Tocantins, Palmas, 9 jul. 2015.

VALLE, Ione Ribeiro. Burocratização da Educação: um estudo sobre o Conselho Estadual de Educação do Estado de Santa Catarina e o seu papel na política de expansão do ensino de $2^{\circ}$ grau. 1991. 360 f. Dissertação (Mestrado em Sociologia Política) - Universidade Federal de Santa Catarina, Florianópolis, 1991. 
Conselhos Estaduais de Educação nos Novos Planos Estaduais de Educação

Rosimar de Fátima Oliveira é professora da Faculdade de Educação da Universidade Federal de Minas Gerais, onde atua no Programa de Pós-Graduação em Educação: Conhecimento e Inclusão Social, Linha de Pesquisa Políticas Públicas de Educação. Doutora em Educação pela Universidade de São Paulo, mestre em Educação pela Universidade Federal de Minas Gerais e graduada em Ciências Sociais (Licenciatura e Bacharelado) pela Universidade Federal de Juiz de Fora.

E-mail: rosimarfoliveira@gmail.com

Donaldo Bello de Souza possui pós-doutorado em Política e Administração Educacional pela Faculdade de Psicologia e de Ciências da Educação (FPCE) da Universidade de Lisboa (UL), Doutorado em Educação pela Universidade Federal do Rio de Janeiro (UFRJ). É Professor Associado no Departamento de Políticas Públicas, Avaliação e Gestão da Educação (DEPAG) na Faculdade de Educação da Universidade do Estado do Rio de Janeiro (UERJ).

E-mail: donaldobello@gmail.com

Adriane Peixoto Câmara é doutoranda em Educação, no Programa de Pós- Graduação em Educação: Conhecimento e Inclusão Social da Faculdade de Educação da UFMG, na Linha de Pesquisa Políticas Públicas em Educação; possui Mestrado em Educação pela Universidade Federal do Rio Grande do Sul, na Linha de Pesquisa Educação, Sexualidade e Relações de Gênero e Graduação em Ciências Sociais (Bacharelado e Licenciatura) pela Universidade Federal de Minas Gerais (2004).

E-mail: adrianecamara@gmail.com 